Heide, I. van der, Wezel, N. van, Blom, M., Spreeuwenberg, P., Devillé, W.L.J.M., Francke, A.L. Effects of an educational intervention on health-related quality of life among family caregivers of people with dementia with a Turkish or Moroccan immigrant background: Insights from a cluster randomised controlled trial. Patient Education and Counseling: 2021, 104(5), p. 1168-1175

$\begin{array}{lll}\text { Postprint version } & : & 2.0 \\ \text { Journal website } & : & \text { https://www.sciencedirect.com/science/article/abs/pii/S0738399120305 } \\ & & 905 ? \text { via\%3Dihub } \\ \text { Pubmed link } & : & \text { https://pubmed.ncbi.nIm.nih.gov/33143906/ } \\ \text { DOI } & : & 10.1016 / \text { j.pec.2020.10.029 }\end{array}$

This is a Nivel certified Post Print, more info at nivel.nl

\title{
Effects of an educational intervention on health- related quality of life among family caregivers of people with dementia with a Turkish or Moroccan immigrant background: Insights from a cluster randomised controlled trial
}

\author{
Iris van der Heide ${ }^{\mathrm{a}, *}$, Nienke van Wezel ${ }^{\mathrm{b}}$, Marco Blom ${ }^{\mathrm{b}}$, Peter \\ Spreeuwenberg ${ }^{a}$, Walter L.J.M. Devilléa, ${ }^{a, c d}$, Anneke L. Francke ${ }^{a, e}$
}

a Nivel, Netherlands Institute of Health Services Research, P.O. Box 1568, 3500 BN Utrecht, Netherlands

b Alzheimer Nederland, Amersfoort, Netherlands

c Faculty of Social and Behavioral Sciences, University of Amsterdam, Amsterdam, Netherlands

d Julius Centre for Health Sciences and Primary Care, University Medical Centre, Utrecht, Netherlands

e Department of Public and Occupational Health, Amsterdam Public Health Research Institute, VU University, Amsterdam, Netherlands

\footnotetext{
Abstract

Objective: Gaining understanding of the health-related quality of life (HRQL) of family caregivers of people with dementia with Turkish or Moroccan immigrant backgrounds and to examine whether an educational peer group intervention can improve HRQL. Methods: Understanding of HRQL and associated variables was obtained by multiple linear regression analyses. The effects of the intervention on HRQL were assessed in multilevel analyses using data collected before the start (baseline), directly after the intervention (one to two weeks after baseline) and three months after the start of the intervention. The intervention (two interactive group sessions) entailed providing information about dementia and care/support options.

Results: At baseline $(n=319), H R Q L$ was moderately and significantly associated with migration background, gender, self-perceived pressure from informal care and the formal and informal support received $(p<.05)$. The intervention had a small effect on
} 
Heide, I. van der, Wezel, N. van, Blom, M., Spreeuwenberg, P., Devillé, W.L.J.M., Francke, A.L. Effects of an educational intervention on health-related quality of life among family caregivers of people with dementia with a Turkish or Moroccan immigrant background: Insights from a cluster randomised controlled trial. Patient Education and Counseling: 2021, 104(5), p. 1168-1175

emotional wellbeing directly after the intervention $(p<.05)$ and on perceived general health status three months after $(p<.05)$.

Conclusion: Culturally sensitive peer group education on dementia and care/support options can to some extent enhance HRQL among family caregivers in the short term. Practice implications: The intervention as described in this study is recommended for supporting family caregivers of people with dementia with Turkish or Moroccan backgrounds.

\section{Introduction}

Taking care of someone with dementia can be burdensome, both mentally and physically [1-4]. Several studies show that the mental and physical consequences of caring for a person with dementia can result in reduced health-related quality of life (HRQL) in family caregivers of people with dementia [4-7]. Yet little is known specifically about the HRQL of caregivers from minority populations or about strategies that could enhance the HRQL in these groups.

In several European countries, including the Netherlands, people with Turkish or Moroccan immigrant backgrounds are among the largest non-Western minority groups. In the Netherlands, a total of 791,000 people were of Turkish or Moroccan origin in 2017, which was $4.6 \%$ of the Dutch population in that year [8]. The first generation of Turkish and Moroccan immigrants, who moved to the Netherlands as labour migrants in the late 1960s and 1970s, have now reached an age in which dementia is becoming increasingly prevalent.

A better picture of the HRQL of family caregivers with a Turkish or Moroccan background who care for a person with dementia is important, given indications that there is a great reliance within these groups on care provided by (female) family members $[9,10]$.

The primary aim of the current study is therefore to provide this insight in relation to sociodemographic and care-related characteristics. We are using the term 'family caregivers' to refer not only to relatives but also to friends, neighbours or others who provide unpaid care for a person with dementia [11].

The secondary aim of this study is to evaluate whether the HRQL of family caregivers with Turkish or Moroccan backgrounds could be enhanced by an educational peer group intervention developed specifically for these groups.

The goal of this intervention was to enhance knowledge about dementia and about care and support options among family caregivers and to facilitate the exchange of experiences between caregivers. The effects of this intervention on knowledge about dementia and on the self-perceived pressure from informal care have been described elsewhere [12]. In the context of the current study, we were interested in the effect of the intervention on HRQL.

The specific research questions that guide the current study are:

1 What is the health-related quality of life of family caregivers of people with dementia with a Turkish or Moroccan background living in the Netherlands?

2 To what extent are sociodemographic characteristics associated with the health-related quality of life in these groups?

3 To what extent are the frequency of caregiving, the selfperceived pressure from informal care and the support received from others in the care for the relative with dementia related to the healthrelated quality of life in these groups?

4 Can the health-related quality of life in these groups be enhanced by the implementation of an educational peer group intervention? 
Heide, I. van der, Wezel, N. van, Blom, M., Spreeuwenberg, P., Devillé, W.L.J.M., Francke, A.L. Effects of an educational intervention on health-related quality of life among family caregivers of people with dementia with a Turkish or Moroccan immigrant background: Insights from a cluster randomised controlled trial. Patient Education and Counseling: 2021, 104(5), p. 1168-1175

We expect the HRQL to be lower in older caregivers, in those who have a lower socioeconomic position and in women $[13,14]$. Secondly, we expect that a poorer HRQL will be associated with a higher frequency of caregiving, a higher self-perceived pressure from informal care and less support from professionals, friends or family members [14-20]. Thirdly, we expect that the social element of the intervention will enhance emotional wellbeing in family caregivers and their engagement in social activities, which are two dimensions of HRQL as measured in this study [21-24].

\section{Methods}

\subsection{Design}

This study is part of a cluster RCT that aims to evaluate the effect of an educational peer group intervention on knowledge about dementia (primary outcome), self-perceived pressure from informal care(secondary outcome) and HRQL (secondary outcome) among family caregivers of people with dementia. The current study includes two components: (a) assessing the HRQL of family caregivers of people with dementia with a Turkish or Moroccan background using baseline data from a cluster randomised controlled trial (cluster RCT) with repeated measurements; (b) evaluating the effect of an educational peer group intervention on the HRQL based on this cluster RCT.

The cluster RCT included a measurement directly before the first educational session (TO, baseline), directly after the second educational session, which was one to two weeks after T0 (T1), and three months after TO (T2). The unit of randomisation was the region in which the family caregivers lived. The study included a total of 16 'clusters', namely regions in the Netherlands that were randomly and blindly assigned to either the intervention or the control condition by an independent researcher.

The cluster RCT design was chosen over an RCT design in which individuals are allocated to the intervention or control conditions for two reasons. Firstly, a cluster RCT did not require participants to travel long distances participate in the intervention, thereby encouraging participation. Secondly, participants under the control conditions could not be influenced by participants living in the same region and receiving the intervention. The CONSORT extension for Cluster Trials was considered for reporting our findings.

Participants who were in a cluster (i.e. region) that was randomly assigned to the control condition completed the same questionnaires as participants in the intervention condition at T0, T1 (one to two weeks after T0) and T2 (three months after T0).

\subsection{Sample size}

We calculated the sample size taking into account the intra-cluster correlation coefficient, the expected effect and the power of the study. In order to detect a difference of $35 \%$ in the primary outcome measure of the cluster RCT (dementia knowledge) with a power of 0.80 and an $\alpha$ of .05, the control and intervention condition should each include 129 participants. In order to account for clustering, the sample size should be enlarged by $10 \%$, leading to a total sample size of 284 . To allow for a $20 \%$ loss during follow-up, a total of 340 participants needed to be included.

\subsection{Participants and recruitment}

The study was performed in regions in the Netherlands where no educational programmes on dementia were already being offered to the target groups and where a relatively large number of people with a Turkish or Moroccan background lived. The eligibility criteria for study participants were: (a) knowing someone with a dementia diagnosis or severe memory problems; (b) being born in Turkey or Morocco or having at least one parent who was born in one of these countries; (d) not having dementia or memory problems themselves. 
Heide, I. van der, Wezel, N. van, Blom, M., Spreeuwenberg, P., Devillé, W.L.J.M., Francke, A.L. Effects of an educational intervention on health-related quality of life among family caregivers of people with dementia with a Turkish or Moroccan immigrant background: Insights from a cluster randomised controlled trial. Patient Education and Counseling: 2021, 104(5), p. 1168-1175

Potential participants were invited to participate by key contacts (e.g. imams, immigrant care organizations or regional departments of Alzheimer Netherlands). If the potential participant was interested in participating, the key contact passed on their contact details to the study coordinator (NvW), after obtaining the consent of the potential participant. The study coordinator assessed whether the potential participant fulfilled all the inclusion criteria. For the purpose of the current paper, a selection was made of participants who stated that they cared for a person with dementia or severe memory problems.

\subsection{Intervention}

Participants in the intervention condition received two educational sessions of two hours each, together with other participants with the same background (Turkish or Moroccan), in a meeting place such as a room in a mosque or in a cultural community centre. In the first session, a trained educator with the same migrant background as the participants explained what the difference was between dementia and 'normal' forgetfulness and that dementia is a brain disease. In the second session, which took place one to two weeks after the first session, the educator facilitated a discussion about the importance of open communication about dementia and about local options for care and support. The educational sessions were provided in the native language of the participants, which was either Turkish or Moroccan Arabic.

Participants in the control condition did not receive the educational peer support sessions. They met three times in similar meeting places with other participants with the same migrant background, but only to complete the questionnaires. The second meet-up for completing the questionnaire took place one to two weeks after the first and the third took place three months after the first. As participants in the control condition also met peer caregivers when filling in the questionnaire, they might have talked to others about their situation. The peer support sessions were also offered to the participants in the control condition, but only after the study ended.

In 15 of the 16 regions, one group consisted of participants with a Turkish background and one consisted of participants with a Moroccan background. In one region, three groups were made up of participants with a Turkish background and one of participants with a Moroccan background. A total of 34 groups were included in the study: 16 of participants with a Moroccan background and 18 of participants with a Turkish background. The groups had a maximum of 30 participants each.

\subsection{Outcomes and measurements}

The HRQL - a secondary outcome measure of the cluster RCT pertaining to the individual participant level - was measured by three dimensions in the COOP/WONCA charts: 1) emotional problems during the past two weeks; 2 ) being hampered in social activities by emotional or physical problems during the past two weeks; and 3) perceived general health status during the past two weeks. Each dimension was assessed by one item. Answers could be given on a 5-point Likert scale that was illustrated by simple drawings of smiling and sad faces, with higher scores indicating a poorer quality of life. The COOP/WONCA charts have been validated for use in Turkish and Moroccan populations [25] and were therefore applied in this study.

To answer the second research question, the sociodemographic characteristics included were age (in years), sex ( $1=$ male; $2=$ female), level of education ( $1=$ no education; 2 = primary education; $3=$ secondary education; $4=$ secondary vocational education; $5=$ higher vocational education; $6=$ university), country of birth ( $1=$ the Netherlands; 2 = other ) and migrant background ( 1 = Turkish; 2 = Moroccan). The level of education was included as a proxy for the socioeconomic position [26].

To answer the third research question, the frequency of caregiving, the self-perceived pressure from informal care and support received from other people were included. Frequency of caregiving was assessed by asking how often people care for their loved one with dementia, with the following 
Heide, I. van der, Wezel, N. van, Blom, M., Spreeuwenberg, P., Devillé, W.L.J.M., Francke, A.L. Effects of an educational intervention on health-related quality of life among family caregivers of people with dementia with a Turkish or Moroccan immigrant background: Insights from a cluster randomised controlled trial. Patient Education and Counseling: 2021, 104(5), p. 1168-1175

answer options: 1 ) on a daily basis; 2 ) three to six times a week; 3 ) maximum of twice a week; 4) less than once a week; 5) less than once a month.

The self-perceived pressure from informal care was assessed by the 'Self Perceived Pressure from Informal Care' (SPPIC) scale (in Dutch called the EDIZ) $[27,28]$. The SPPIC was originally developed and validated in Dutch, but has also been validated in Turkish [29]. The SPPIC scale involves nine items and answers can be given on a 5-point Likert scale ranging from 1 (no burden of care) to 5 (high burden of care). Sum scores were calculated ranging from 9 to 45 , with higher scores indicating a higher perceived care burden.

Support received from other people in the care for the relative with dementia was measured using four questions developed by the research team, asking whether participants received 1 ) advice from their GP or another doctor; 2) support from family; 3) support from friends or neighbours; 4) support from home care staff in the care for a person with dementia. Answers could be given on a five-point Likert scale including the following range: 1 (No!) 2 (No) 3 (More or less) 4 (Yes) 5 (Yes!).

All participants had the option of filling in the questionnaires in Dutch, Moroccan Arabic or Turkish. None of the participants chose to fill in the Moroccan Arabic version of the questionnaire. On all three measurement dates, a majority of the participants with a Turkish background filled in the Turkish version of the questionnaire ( $87 \%$ at T0, $88 \%$ at T1 and $96 \%$ at T2). For those who had poor literacy skills, a research assistant read the questionnaire out loud and wrote down the participant's answers to the questions on their behalf.

\section{[Figure 1]}

\subsection{Ethical procedures}

Before participation, participants were informed face-to-face about the study by the key contact who recruited them, then a second time by the study coordinator over the phone and thirdly in an information letter that they received at home before the first meeting.

In the first meeting (TO), all participants received another copy of the information letter and an informed consent form in their language of preference (Dutch, Turkish or Moroccan Arabic). The information letters and informed consent forms were read out loud by a research assistant in cases where a participant had poor literacy skills to ensure that all participants understood the information letter and the informed consent form. The informed consent forms were provided during the first meeting (not sent by post) to ensure that participants themselves provided consent and not a family member. For this study, permission from a medical ethics committee was not required according to Dutch law as the study did not concern medical research and participants were not required to follow rules of behaviour (https://english.ccmo.nl/investigators/legal-framework-for-medicalscientific-research/your-research-is-it-subject-to-the-wmo-or-not).

\subsection{Statistical analyses}

Descriptive statistics were calculated to describe the sociodemographic characteristics and the HRQL of family caregivers using the baseline data. Three multiple linear regression analyses were then conducted using the baseline data to estimate the association between the three dimensions of $\mathrm{HRQL}$ as the dependent variables (emotional problems, being hampered in social activities, and perceived general health status) and age, sex, level of education, migrant background, country of birth, frequency of caregiving, self-perceived pressure from informal care and support received as the independent variables. All independent variables were included simultaneously in the regression models. To examine the effect of the intervention on the HRQL, three repeated measures multi-level analyses were conducted, taking into account the effects of clustering at the region level. Each analysis used a different dimension of the HRQL as the outcome variable. At the participant level, an 
Heide, I. van der, Wezel, N. van, Blom, M., Spreeuwenberg, P., Devillé, W.L.J.M., Francke, A.L. Effects of an educational intervention on health-related quality of life among family caregivers of people with dementia with a Turkish or Moroccan immigrant background: Insights from a cluster randomised controlled trial. Patient Education and Counseling: 2021, 104(5), p. 1168-1175

unstructured covariance structure between the three measurement points was modelled to control for the correlation between measurements within participants. This was done separately for the control and intervention conditions. Differences in the mean HRQL scores in the intervention and the control condition at T1 and T2 compared with T0 were estimated, adjusted for age, sex, level of education, migrant background, country of birth, frequency of caregiving and self-perceived pressure from informal care. Analyses were based on a treatment allocation framework: all participants were analysed as part of the condition (intervention or control) to which they had been allocated. The descriptive statistics and linear regression analyses were conducted in STATA version 14 and the multi-level analyses in MlwiN. In multi-level analyses, participants are only included if they have at least one completed outcome measure (at T0, T1 and/or T2) and no missing data on any of the background characteristics that were included in the analysis (such as gender and age).

\section{Results}

\subsection{Participants}

A total of 288 eligible participants were from regions assigned to the intervention condition and 262 from regions assigned to the control condition; see Fig. 1. A total of 386 participants provided family care. Of this group, 319 participants filled in the questionnaire at T0, 313 at T1 and 290 at T2.

\subsection{Background characteristics}

Table 1 shows the background characteristics of the participants of Turkish or Moroccan origin who were included in the analyses. The proportion who were female, born in the Netherlands and had no education was higher for participants with Moroccan backgrounds than for Turkish backgrounds.

\subsection{Health-related quality of life}

A total of 180 caregivers with a Turkish background and 139 caregivers with a Moroccan background filled in a questionnaire at the baseline. The mean HRQL scores per dimension for each of these groups are presented in Table 2 on a scale from 1 (good HRQL) to 5 (poor HRQL) as well as the percentages for each category.

Especially with respect to emotional problems, participants with a Turkish background show poorer outcomes than participants with a Moroccan background: $41.6 \%$ of the participants with a Turkish background gave a ' 4 ' or a ' 5 ' (the worst two categories) where this only applied to $16.6 \%$ in the participants with a Moroccan background.

Of participants with a Turkish background, $19.5 \%$ were hampered quite a bit or very often in their social activities by emotional or physical problems, compared with $15.9 \%$ of participants with a Moroccan background.

The majority of the participants with a Turkish background, namely $62.7 \%$, perceived their general health status to be fair to poor, compared with $38.4 \%$ of the participants with a Moroccan background.

The overall mean score is 3.0 for participants with a Turkish background and 2.5 for participants with a Moroccan background, implying moderate overall HRQL for both groups. 
Heide, I. van der, Wezel, N. van, Blom, M., Spreeuwenberg, P., Devillé, W.L.J.M., Francke, A.L. Effects of an educational intervention on health-related quality of life among family caregivers of people with dementia with a Turkish or Moroccan immigrant background: Insights from a cluster randomised controlled trial. Patient Education and Counseling: 2021, 104(5), p. 1168-1175

\section{[Table 2]}

\subsection{Associations between health-related quality of life, sociodemographic and care- related characteristics}

The results of the multiple linear regression analyses as presented in Table 3 show that at the baseline, family caregivers with a Turkish background have had significantly more emotional problems during the last two weeks $(B=-0.74(S E=0.16) p<.01)$, are more often hampered in social activities $(B=-0.32(S E=0.14) ; p<.05) ; p<.01)$ and report poorer perceived general health status $(B=-0.58(S E=0.13 ; p<.01)$ than caregivers with a Moroccan background.

Furthermore, female caregivers were more likely to report emotional problems ( $B=0.59$ (SE $=$ $0.25) ; p<.05)$ and being hampered in social activities because of emotional or physical problems $(B=$ $0.48(\mathrm{SE}=0.23) ; \mathrm{p}<.05)$ than male caregivers.

In addition, a higher self-perceived pressure from informal care was significantly associated with more emotional problems during the last two weeks $(B=0.05$ ( $S E=0.10) ; p<.01$ ), being hampered in social activities more often $(B=0.06(S E=0.01) ; p<.01)$ and poorer perceived general health status $(B=0.04(S E=0.01) ; p<.01)$.

With respect to support received from other people in caring for the relative with dementia, more support from family was associated with fewer emotional problems $(B=-0.18(S E=0.06) ; p<.01)$ and with a better perceived general health status $(B=-0.13(S E=0.05) ; p<.05)$. In addition, more support from home care staff was associated with fewer emotional problems $(B=-0.13(S E=0.07) ; p<.05)$. In contrast, more support from friends or neighbours was associated with more emotional problems ( $B$ $=0.15(\mathrm{SE}=0.07) ; \mathrm{p}<.05)$.

Country of birth, level of education, frequency of caregiving and advice from a doctor were not associated with the HRQL, according to on the outcomes of these multiple regression models.

\section{[Table 3]}

\subsection{Effect of the educational peer group intervention}

The effects of the educational peer group intervention on the HRQL in family caregivers are presented in Table 4. In the intervention condition, the mean score for perceived emotional problems during the last two weeks was significantly lower at T1 compared with T0 (mean: 2.47 versus 2.86; $\operatorname{chi} 2(1)=16.20 ; p<.001)$. However, this was not a lasting decrease, as the mean score at T2 was higher than the mean score at T0. No significant differences over time were found in the control condition with respect to perceived emotional problems.

With respect to being hampered in social activities, there seemed to be an increase over time in mean scores in both the intervention and the control condition, implying that participants were increasingly hampered in their social activities, yet these trends are not significant in either group.

On the other hand, Table 4 shows a small but significant trend towards improved perceived general health status in the intervention condition. Although the decrease in the mean score at T1 (mean: 3.33) compared with T0 (mean: 3.45 ) is not significant, the decrease in the mean score at T2 (mean: 3.22 ) compared with T0 is significant (chi2 $(1)=6.15 ; p<.05)$. No such decrease is found in the control condition, where scores seem to increase over time, although not significantly, implying poorer HRQL. 
Heide, I. van der, Wezel, N. van, Blom, M., Spreeuwenberg, P., Devillé, W.L.J.M., Francke, A.L. Effects of an educational intervention on health-related quality of life among family caregivers of people with dementia with a Turkish or Moroccan immigrant background: Insights from a cluster randomised controlled trial. Patient Education and Counseling: 2021, 104(5), p. 1168-1175

\section{Discussion and conclusion}

\subsection{Discussion}

Generally, the HRQL of family caregivers with a Turkish or Moroccan immigrant background is moderate. To assess whether the HRQL scores that we found in our study differ from the HRQL in non-caregivers, we looked at a study using Dutch census data. This study reported on the perceived health status, which is one dimension of the HRQL. It showed that $68 \%$ of Dutch inhabitants with a Turkish background and $64 \%$ of Dutch inhabitants with a Moroccan background perceive their health to be good or very good, compared with $37 \%$ and $62 \%$ respectively of the participants in our study [30]. This implies that family caregivers with a Turkish background have a much poorer perceived health status than Dutch inhabitants with a Turkish background in general. In comparison, $83 \%$ of the Dutch inhabitants without a migration background perceive their health as good or very good [30].

A recent study found that $19 \%$ of all Dutch adult inhabitants with non-Western migration backgrounds perceived their psychological wellbeing as poor [31]. In comparison, we found $42 \%$ and $17 \%$ of the family caregivers with a Turkish or Moroccan immigrant backgrounds respectively to have experienced emotional problems quite a bit or extremely often. This implies that family caregivers with a Turkish background have more emotional problems than people with a non-Western migration background in the general population. Further research is needed to explain the relatively poor quality-of-life scores in family caregivers with a Turkish background.

With respect to country of birth (either The Netherlands, Turkey or Morocco), we did find an initial association with perceived general health status, which is one aspect of HRQL, based on univariate regression analysis (data not shown). However, in the multivariate regression model this association was no longer significant, implying that other variables (including age and gender) account for this association. It therefore appears that country of birth does not explain any unique variance in the HRQL of family caregivers with a Turkish or Moroccan immigrant background.

In addition, we found that the quality of life of female caregivers was lower than the quality of life of male caregivers; this was also reported in previous research [13]. This can probably be explained by the fact that women are more likely to provide the domestic and physical care for a relative with dementia [32,33], while male caregivers often provide other types of help, such as administrative or transport tasks [34], which might involve less of a care burden.

\section{[Table 4]}

Moreover, we found that the HRQL was strongly associated with the self-perceived pressure from informal care. Such an association was not found between the HRQL and the frequency of caregiving. Although various studies suggest that perceived pressure from informal care is one of the strongest predictors of quality of life in family caregivers $[15,17]$, there is also evidence that the frequency of caregiving is related to quality of life when controlling for the care pressure [17]. However, our findings suggest that among family caregivers with a Turkish or Moroccan immigrant background, the self-perceived pressure from informal care is more strongly related to the HRQL than the frequency of caregiving.

There are few comparable studies on the effects of support from others on HRQL in family caregivers of people with dementia [20,35]. However, our finding that receiving support from home care staff is associated with better emotional wellbeing is in line with the findings of Rosness and colleagues, who found a reduction in depression symptoms in family caregivers of people who received nursing care [20]. Remarkably, we found that more support from family and from homecare staff was associated with better emotional wellbeing, whereas more support from friends or neighbours was associated with worse emotional wellbeing. Further research is recommended to 
Heide, I. van der, Wezel, N. van, Blom, M., Spreeuwenberg, P., Devillé, W.L.J.M., Francke, A.L. Effects of an educational intervention on health-related quality of life among family caregivers of people with dementia with a Turkish or Moroccan immigrant background: Insights from a cluster randomised controlled trial. Patient Education and Counseling: 2021, 104(5), p. 1168-1175

explore the roles of different types of support in the emotional wellbeing of family caregivers with a Turkish or Moroccan background.

We expected that contact with peers would have a positive effect on emotional and social wellbeing, as found in four other educational intervention studies among caregivers of people with dementia [21-24]. We found an initial improvement in emotional wellbeing, although this positive effect was no longer present three months after the start of the intervention. To achieve a more long-lasting effect on emotional wellbeing, it might be necessary to increase the number of sessions and to prolong the intervention period.

Furthermore, no effect of the intervention was found for the dimension regarding social activities in relation to emotional and physical problems. Two sessions might not be enough to achieve effects on this dimension either.

We did find a small effect of the intervention on perceived general health status, three months after the start of the intervention. A possible explanation for the small improvement in the general health status could lie in the assumption that the intervention led to more awareness about support options and consequently more actual support, which might have had an alleviating effect on family caregivers, thereby positively affecting their wellbeing.

A limitation of the current study is that we did not measure any long-term effects of the intervention, because of limited resources. It would be valuable to examine in the long term whether interventions, like the intervention evaluated in the current study, actually encourage people to make use of informal or professional care and support options and whether this has a beneficial effect on the quality of life and coping with dementia. The initial findings of our study, indicating effects (albeit small) of the HRQL intervention among family caregivers with immigrant backgrounds, therefore serve as grounds for conducting further research into the long-term effects of the intervention.

Another limitation is that we were unable to allow for the severity of dementia in the analyses. However, earlier research indicates that subjective experiences of family caregivers, such as feelings of being overburdened, are better predictors of the quality of life in family caregivers than the level of cognitive impairment of the person with dementia $[15,36]$. This implies that the main results of the current study would probably not have been different if the severity of dementia had been included in the regression models. Ideally, information about the severity of dementia would have been obtained from an healthcare professional involved, for instance a GP.

\subsection{Conclusion}

Overall, the HRQL of family caregivers with Turkish or Moroccan immigrant backgrounds tends to be moderate. A greater self-perceived pressure from informal care is related to a poorer HRQL in these groups. The HRQL was found to be lower in female than in male caregivers and in caregivers with a Turkish background compared with caregivers with a Moroccan background. Culturally sensitive peer group education on dementia and on local care and support options has a small but positive effect on two dimensions of the HRQL in family caregivers shortly after it is provided.

\subsection{Practice implications}

In order to support family caregivers of people with dementia with a Turkish or Moroccan background, it is recommended that culturally sensitive peer group education on dementia and on local care and support options should be offered. Sufficient time for reaching and informing the target population is crucial for successful implementation of the intervention in other settings.

\section{CRediT authorship contribution statement}


Heide, I. van der, Wezel, N. van, Blom, M., Spreeuwenberg, P., Devillé, W.L.J.M., Francke, A.L. Effects of an educational intervention on health-related quality of life among family caregivers of people with dementia with a Turkish or Moroccan immigrant background: Insights from a cluster randomised controlled trial. Patient Education and Counseling: 2021, 104(5), p. 1168-1175

Iris van der Heide: Conceptualization, Methodology, Formal analysis, Data curation, Writing original draft. Nienke van Wezel: Conceptualization, Investigation, Writing - review \& editing, Project administration. Marco Blom: Methodology, Formal analysis, Writing - review \& editing. Peter Spreeuwenberg: Conceptualization, Writing - review \& editing, Supervision. Walter L.J.M. Devillé: Conceptualization, Methodology, Writing - review \& editing, Supervision. Anneke L. Francke: Conceptualization, Writing - review \& editing, Supervision.

\section{Acknowledgement}

This work was supported by 'Alzheimer Nederland'.

\section{References}

[1] H. Brodaty, M. Donkin, Family caregivers of people with dementia, Dialogues Clin. Neurosci. 11 (2009) 217-228.

[2] M. Pinquart, S. Sörensen, Differences between caregivers and noncaregivers in psychological health and physical health: a meta-analysis, Psychol. Aging 18 (2003) 250-267.

[3] M. Pinquart, S. Sörensen, Correlates of physical health of informal caregivers: a meta-analysis, J. Gerontol. B Psychol. Sci. Soc. Sci. 62 (2007) 126-137.

[4] M.H. Bleijlevens, M. Stolt, A. Stephan, A. Zabalegui, K. Saks, C. Sutcliffe, C. Lethin, M.E. Soto, S.M. Zwakhalen, RightTimePlaceCare Consortium, Changes in caregiver burden and healthrelated quality of life of informal caregivers of older people with Dementia: evidence from the European RightTimePlaceCare prospective cohort study, J. Adv. Nurs. 71 (2015) 1378-1391, doi:http://dx.doi. org/10.1111/jan.12561.

[5] S. Alltag, I. Conrad, S.G. Riedel-Heller, Caregiver burden among older informal caregivers of patients with dementia and its influence on quality of life : a systematic literature review, Z. Gerontol. Geriatr. 52 (2019) 477-486, doi: http://dx.doi.org/10.1007/s00391-018-1424-6.

[6] I. Conrad, S. Alltag, H. Matschinger, R. Kilian, S.G. Riedel-Heller, Quality of life among older informal caregivers of people with dementia, Nervenarzt 89 (2018) 500-508, doi:http://dx.doi.org/10.1007/s00115-018-0510-8.

[7] N.M. Stall, S.J. Kim, K.A. Hardacre, P.S. Shah, S.E. Straus, S.E. Bronskill, L.M. Lix, C. M. Bell, P.A. Rochon, Association of informal caregiver distress with health outcomes of community-dwelling dementia care recipients: a systematic review, J. Am. Geriatr. Soc. 67 (2019) 609-617, doi:http://dx.doi.org/10.1111/jgs.15690.

[8] Statistics Netherlands, [Population; statistics]. https://opendata.cbs.nl/statline/\#/CBS/nl/dataset/37296ned/table?dl=107C4, (accessed 30 October 2019).

[9] N. van Wezel, A.L. Francke, E. Kayan-Acun, W.L.J.M. Devillé, N.J. Van Grondelle, M.M. Blom, Family care for immigrants with dementia: the perspectives of female family carers living in the Netherlands, Dementia (London) 15 (2016) 69-84, doi:http://dx.doi.org/10.1177/1471301213517703.

[10] N. van Wezel, A.L. Francke, E. Kayan Acun, W.L.J.M. Devillé, N.J. van Grondelle, M.M. Blom, Explanatory models and openness about dementia in migrant communities: aqualitative study among female family carers, Dementia (London) 17 (2018) 840-857, doi:http://dx.doi.org/10.1177/1471301216655236.

[11] N.M. Stall, A. Campbell, M. Reddy, P.A. Rochon, Words Matter, The language of family caregiving, J. Am. Geriatr. Soc. 67 (2019) 2008-2010, doi:http://dx.doi.org/10.1111/jgs.15988.

[12] N. van Wezel, I. van der Heide, W.L.J.M. Devillé, E.K. Acun, J.H.C.M. Meerveld, P. Spreeuwenberg, M.M. Blom, A.L. Francke, Effects of an educational peer group intervention on 
Heide, I. van der, Wezel, N. van, Blom, M., Spreeuwenberg, P., Devillé, W.L.J.M., Francke, A.L. Effects of an educational intervention on health-related quality of life among family caregivers of people with dementia with a Turkish or Moroccan immigrant background: Insights from a cluster randomised controlled trial. Patient Education and Counseling: 2021, 104(5), p. 1168-1175

dementia knowledge of family caregivers with a Turkish or Moroccan immigrant background: a cluster randomised controlled trial, Forthcoming a.

[13] H. Kim, M. Chang, K. Rose, S. Kim, Predictors of caregiver burden in caregivers of individuals with dementia, J. Adv. Nurs. 68 (2012) 846-855, doi:http://dx.doi.org/10.1111/j.1365-

2648.2011.05787.x.

[14] K.C. Tay, C.C. Seow, C. Xiao, H.M. Lee, H.F. Chiu, S.W. Chan, Structured interviews examining the burden, coping, self-efficacy, and quality of life among family caregivers of persons with dementia in Singapore, Dementia (London) 15 (2016) 204-220, doi:http://dx.doi.org/10.1177/1471301214522047.

[15] I. Abdollahpour, S. Nedjat, Y. Salimi, M. Noroozian, R. Majdzadeh, Which variable is the strongest adjusted predictor of quality of life in caregivers of patients with dementia? Psychogeriatrics 15 (2015) 51-57, doi:http://dx.doi.org/10.1111/psyg.12094.

[16] C.M. Bell, S.S. Araki, P.J. Neumann, The association between caregiver burden and caregiver health-related quality of life in Alzheimer disease, Alzheimer Dis. Assoc. Disord. 15 (2001) 129136.

[17] N.L. Chappell, R.C. Reid, Burden and well-being among caregivers: examining the Distinction, Gerontologist 42 (2002) 772-780.

[18] E.P. Janssen, M. de Vugt, S. Köhler, C. Wolfs, L. Kerpershoek, R.L. Handels, M. Orrell, B. Woods, H. Jelley, A. Stephan, A. Bieber, G. Meyer, K. Engedal, G. Selbaek, A. Wimo, K. Irving, L. Hopper, M. Gonçalves-Pereira, E. Portolani, O. Zanetti, F.R. Verhey, Caregiver profiles in dementia related to quality of life, depression and perseverance time in the European Actifcare study: the importance of social health, Aging Ment. Health 21 (2017) 49-57, doi:http://dx.doi.org/10.1080/13607863.2016.1255716.

[19] E. Papastavrou, P. Andreou, N. Middleton, S. Papacostas, I.K. Georgiou, Factors associated with quality of life among family members of patients with dementia in Cyprus, Int. Psychogeriatr. 26 (2014) 443-452, doi:http://dx.doi.org/10.1017/S104161021300224X.

[20] T.A. Rosness, M. Mjørud, K. Engedal, Quality of life and depression in carers of patients with early onset dementia, Aging Ment. Health 15 (2011) 299-306, doi:http://dx.doi.org/10.1080/13607861003713224.

[21] A. Kurz, S. Wagenpfeil, J. Hallauer, H. Schneider-Schelte, S. Jansen; AENEAS, Study, Evaluation of a brief educational program for dementia carers: the AENEAS study, Int. J. Geriatr. Psychiatry 25 (2010) 861-869, doi:http://dx.doi.org/10.1002/gps.2428.

[22] S. Pihet, S. Kipfer, Coping with dementia caregiving: a mixed-methods study on feasibility and benefits of a psycho-educative group program, BMC Geriatr. 18 (2018), doi:http://dx.doi.org/10.1186/s12877-018-0896-y 209.

[23] M. Guerra, C.P. Ferri, M. Fonseca, S. Banerjee, M. Prince, Helping carers to care: the $10 / 66$ dementia research group's randomized control trial of a caregiver intervention in Peru, Braz J Psychiatry 33 (2011) 47-54.

[24] M. Martín-Carrasco, M.F. Martín, C.P. Valero, P.R. Millán, C.I. García, S.R. Montalbán, A.L. Vázquez, S.P. Piris, M.B. Vilanova, Effectiveness of a psychoeducational intervention program in the reduction of caregiver burden in Alzheimer's disease patients' caregivers, Int. J. Geriatr. Psychiatry 24 (2009) 489-499, doi:http://dx.doi.org/10.1002/gps.2142.

[25] R. Hoopman, C.B. Terwee, N.K. Aaronson, Translated COOP/WONCA charts 'found appropriate for use among Turkish and Moroccan ethnic minority cancer patients, J. Clin. Epidemiol. 61 (2008) 1036-1048, doi:http://dx.doi.org/ 10.1016/j.jclinepi.2007.11.018.

[26] R.A. Miech, R.M. Hauser, Socioeconomic status and health at midlife. A comparison of educational attainment with occupation-based indicators, Ann. Epidemiol. 11 (2001) 75-84.

[27] A.M. Pot, R. van Dyck, D.J.H. Deeg, Perceived burden by informal care; construction of a scale, Tijdschrift voor Gerontologie en Geriatrie 26 (1995) 214-219. 
Heide, I. van der, Wezel, N. van, Blom, M., Spreeuwenberg, P., Devillé, W.L.J.M., Francke, A.L. Effects of an educational intervention on health-related quality of life among family caregivers of people with dementia with a Turkish or Moroccan immigrant background: Insights from a cluster randomised controlled trial. Patient Education and Counseling: 2021, 104(5), p. 1168-1175

[28] A.M. Pot, D.J. Deeg, R. van Dyck, C. Jonker, Psychological distress of caregivers: the mediator effect of caregiving appraisal, Patient Educ. Couns. 34 (1998) 43-51, doi:http://dx.doi.org/10.1016/s07383991(98)00048-2 PMID: 9697556.

[29] N. van Wezel, I. van der Heide, G. Duran, W.L.J.M Devillé, R. Hoopman, M.M. Blom, A.M. Pot, A.L. Francke, The Turkish version of the EDIZ validated among informal caregivers with a Turkish immigrant background, Forthcoming $b$.

[30] Statistics Netherlands, [Health]. https://www.cbs.nl/nl nl/achtergrond/2018/47/gezondheid, 2019 (accessed 21 November 2019).

[31] A. Wennekers, J. Boelhouwer, C. van Campen, J. Kullberg, The social state of the Netherlands 2019], Sociaal Cultureel Planbureau, Den Hague, 2019.

[32] M. Del Río Lozano, M.D.M. García-Calvente, J. Calle-Romero, M. Machón- Sobrado, I. LarrañagaPadilla, Health-related quality of life in Spanish informal caregivers: gender differences and support received, Qual. Life Res. 26 (2017) 3227-3238, doi:http://dx.doi.org/10.1007/s11136017-1678-2.

[33] M.N. Rodríguez-Madrid, M. Del Río-Lozano, R. Fernandez-Peña, J. Jiménez-Pernett, L. GarcíaMochón, A. Lupiañez-Castillo, M.D.M. García-Calvente, Gender differences in social support received by informal caregivers: a personal network analysis approach, Int. J. Environ. Res. Public Health 16 (2018), doi:http://dx.doi.org/10.3390/ijerph16010091 pii: E91.

[34] J.R. Kahn, B.S. McGill, S.M. Bianchi, Help to family and friends: are there gender differences at older ages? J. Marriage Fam. 73 (2011) 77-92.

[35] A. Waite, P. Bebbington, M. Skelton-Robinson, M. Orrell, Social factors and depression in carers of people with dementia, Int. J. Geriatr. Psychiatry 19 (2004) 582-587, doi:http://dx.doi.org/10.1002/gps.1136.

[36] M. Takai, M. Takahashi, Y. Iwamitsu, S. Oishi, H. Miyaoka, Subjective experiences of family caregivers of patients with dementia as predictive factors of quality of life, Psychogeriatrics 11 (2011) 98-104, doi:http://dx.doi.org/10.1111/j.1479-8301.2011.00354.x. 
Heide, I. van der, Wezel, N. van, Blom, M., Spreeuwenberg, P., Devillé, W.L.J.M., Francke, A.L. Effects of an educational intervention on health-related quality of life among family caregivers of people with dementia with a Turkish or Moroccan immigrant background: Insights from a cluster randomised controlled trial. Patient Education and Counseling: 2021, 104(5), p. 1168-1175

\section{[Tables and figures]}

Figure. 1: Health-related quality of life (HRQL) scores as measured at baseline ranging from 1 (good $H R Q L$ ) to 5 (poor HRQL).

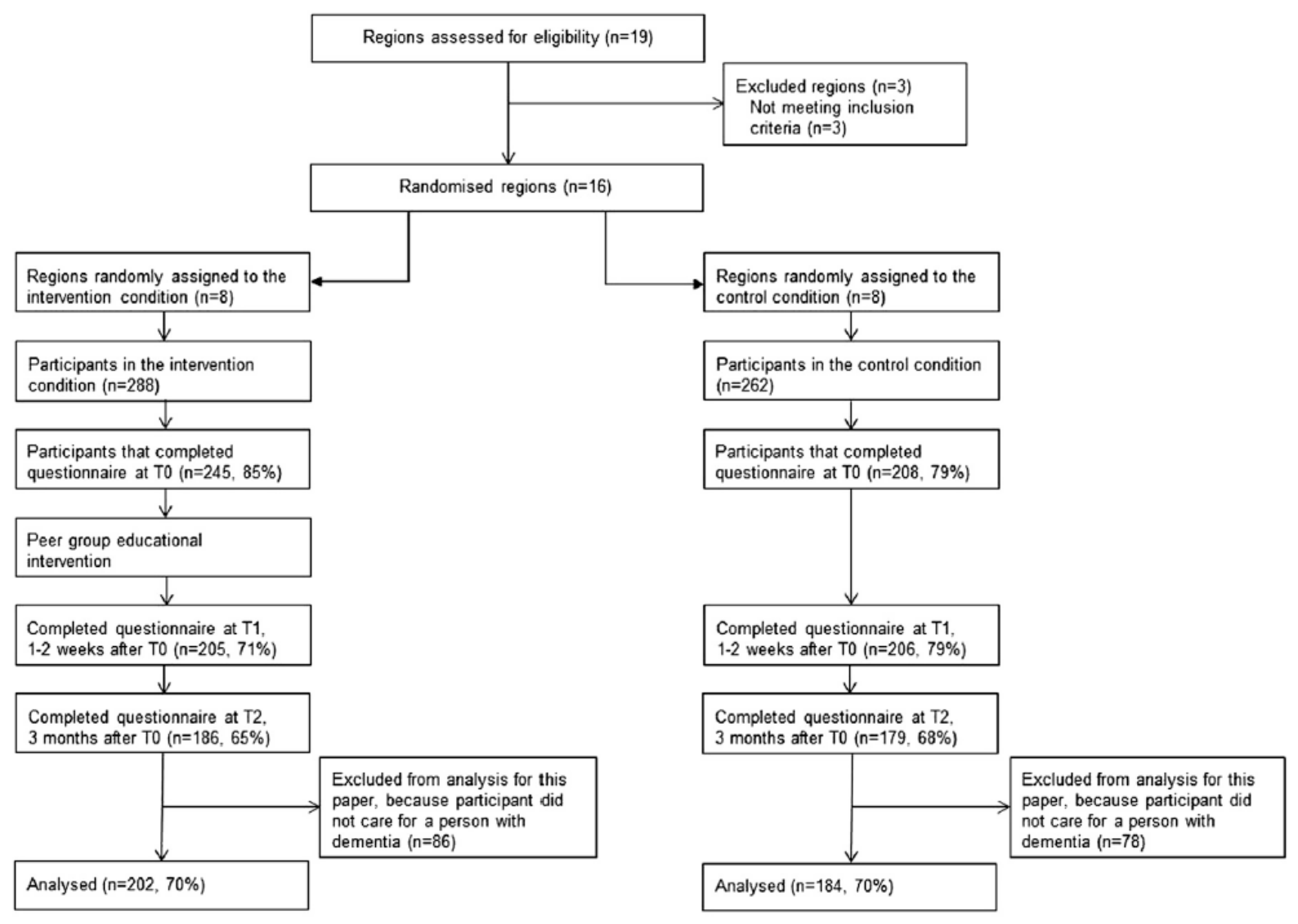

Table 1: Participants' background characteristics

\begin{tabular}{|c|c|c|}
\hline & Participants with a Turkish background $(n=180)$ & Participants with a Moroccan background $(n=139)$ \\
\hline Age, mean (SD) & $45.4(13.8)$ & $41.0(12.7)$ \\
\hline \multicolumn{3}{|l|}{ Sex, \% } \\
\hline Male & 18.9 & 7.9 \\
\hline Female & 81.1 & 91.4 \\
\hline Missing & 0 & 0.7 \\
\hline \multicolumn{3}{|l|}{ Country of birth, \% } \\
\hline Netherlands & 12.8 & 23.7 \\
\hline Other & 86.7 & 75.5 \\
\hline Missing & 0.6 & 0.7 \\
\hline \multicolumn{3}{|l|}{ Level of education, \% } \\
\hline No education & 8.3 & 22.3 \\
\hline Primary education & 35.6 & 14.4 \\
\hline Secondary education & 18.9 & 13.0 \\
\hline Secondary vocational education & 21.1 & 26.6 \\
\hline Higher vocational education & 11.1 & 18.0 \\
\hline University & 3.9 & 5.7 \\
\hline Missing & 1.1 & 0 \\
\hline
\end{tabular}


Heide, I. van der, Wezel, N. van, Blom, M., Spreeuwenberg, P., Devillé, W.L.J.M., Francke, A.L. Effects of an educational intervention on health-related quality of life among family caregivers of people with dementia with a Turkish or Moroccan immigrant background: Insights from a cluster randomised controlled trial. Patient Education and Counseling: 2021, 104(5), p. 1168-1175

Table 2 Health-related quality of life (HRQL) scores as measured at baseline ranging from 1 (good $H R Q L$ ) to 5 (poor HRQL).

\begin{tabular}{lll}
\hline Quality of life dimensions & $\begin{array}{l}\text { Participants with a Turkish background } \\
(\mathrm{n}=180)\end{array}$ & $\begin{array}{l}\text { Participants with a Moroccan background } \\
(\mathrm{n}=139)\end{array}$ \\
\hline Emotional problems, mean (SD) & $3.0(1.3)$ & $2.3(1.3)$ \\
1. Not at all, \% & 14.6 & 32.4 \\
2. Slightly, \% & 23.0 & 32.4 \\
3. Moderately, \% & 20.8 & 7.2 \\
4. Quite a bit, \% & 27.0 & 9.4 \\
5. Extremely, \% & 14.6 & $2.1(1.2)$ \\
Being hampered in social activities by emotional or physical problems, & $2.4(1.2)$ & 41.3 \\
mean (SD) & 28.5 & 29.7 \\
1. Not at all, \% & 29.1 & 13.0 \\
2. Slightly, \% & 22.9 & 10.1 \\
3. Moderately, \% & 15.6 & 5.8 \\
4. Quite a bit, \% & 3.9 & $3.0(1.1)$ \\
5. Extremely, \% & $3.6(0.9)$ & 13.0 \\
Perceived general health status, mean (SD) & 1.7 & 16.7 \\
1. Excellent, \% & 9.6 & 31.9 \\
2. Very good, \% & 26.0 & 30.4 \\
3. Good, \% & 48.0 & 8.0 \\
4. Fair, \% & 14.7 & \\
5. Poor, \% & & \\
\hline
\end{tabular}

Table 3 Associations between health-related quality of life, sociodemographic characteristics, frequency of caregiving, self-perceived pressure from informal care and received support as measured at baseline.

\begin{tabular}{|c|c|c|c|}
\hline \multirow[t]{2}{*}{ Explanatory variables } & \multicolumn{3}{|c|}{ Health-related quality of life dimension ${ }^{a}$} \\
\hline & $\begin{array}{l}\text { Emotional problems } \\
\text { B (SE) }\end{array}$ & $\begin{array}{l}\text { Being hampered in social activities by } \\
\text { emotional or physical problems } \\
\text { B (SE) }\end{array}$ & $\begin{array}{l}\text { Perceived general health status } \\
\text { B (SE) }\end{array}$ \\
\hline Age & $0.004(0.008)$ & $0.009(0.007)$ & $0.010(0.006)$ \\
\hline $\begin{array}{l}\text { Migrant background } \\
\text { (reference group: Turkish) }\end{array}$ & $-0.735(0.156)^{* *}$ & $-0.322(0.143)^{*}$ & $-0.576(0.126)^{* *}$ \\
\hline $\begin{array}{l}\text { Sex } \\
\text { (reference group: male) }\end{array}$ & $0.586(0.249)^{*}$ & $0.482(0.229)^{*}$ & $0.347(0.202)$ \\
\hline $\begin{array}{l}\text { Country of birth } \\
\text { (reference group: the Netherlands) }\end{array}$ & $-0.390(0.233)$ & $-0.316(0.214)$ & $0.053(0.192)$ \\
\hline Level of education & $-0.080(0.063)$ & $0.013(0.058)$ & $-0.069(0.051)$ \\
\hline Frequency of caregiving ${ }^{b}$ & $-0.012(0.060)$ & $0.047(0.055)$ & $-0.044(0.049)$ \\
\hline Self-perceived pressure from informal care ${ }^{a}$ & $0.049(0.100)^{* *}$ & $0.055(0.010)^{* *}$ & $0.036(0.008)^{* *}$ \\
\hline Received advice from doctor ${ }^{c}$ & $0.032(0.068)$ & $0.026(0.063)$ & $-0.031(0.055)$ \\
\hline Received support from family $^{c}$ & $-0.179(0.064)^{* *}$ & $-0.066(0.059)$ & $-0.130(0.052)^{*}$ \\
\hline Received support from friends/neighbours ${ }^{c}$ & $0.149(0.072)^{*}$ & $0.074(0.066)$ & $0.038(0.058)$ \\
\hline Received support from home-care staff ${ }^{c}$ & $-0.132(0.065)^{*}$ & $-0.073(0.061)$ & $-0.043(0.053)$ \\
\hline $\begin{array}{l}\text { Significant association }(\mathrm{p}<.05) \text {. } \\
\text { Significant association }(\mathrm{p}<.01) \text {. } \\
\text { a Higher scores refer to a poorer quality of li } \\
\text { b } \text { Higher scores refer to a lower frequency of }\end{array}$ & ressure from info & & \\
\hline
\end{tabular}

Table 4 Mean health-related quality of life at TO, T1 and T2 for the intervention condition and the control condition.

\begin{tabular}{|c|c|c|}
\hline & Intervention condition $(n=202)$ & Control condition $(\mathrm{n}=184)$ \\
\hline \multicolumn{3}{|l|}{ Perceived emotional problems } \\
\hline T0, mean $(95 \% \mathrm{CI})^{\mathrm{a}}$ & $2.86(2.60-3.12)$ & $2.60(2.37-2.83)$ \\
\hline $\mathrm{T} 1$, mean $(95 \% \mathrm{Cl})^{\mathrm{a}}$ & $2.47(2.23-2.71)$ & $2.72(2.50-2.94)$ \\
\hline $\mathrm{T} 2$, mean $(95 \% \mathrm{CI})^{\mathrm{a}}$ & $2.89(2.62-3.16)$ & $2.67(2.45-2.88)$ \\
\hline Does $\mathrm{T} 1$ differ significantly from $\mathrm{T} 0$ ? $\mathrm{Chi}^{2}(d f) ; \mathrm{p}$-value & $16.20(1) ; p<.001$ & $1.23(1) ; \mathrm{p}>.1$ \\
\hline Does $\mathrm{T} 2$ significantly differ from $\mathrm{T} 0$ ? $\mathrm{Chi}^{2}(d f) ; \mathrm{p}$-value & $0.05(1) ; p>1$ & $0.44(1) ; \mathrm{p}>.1$ \\
\hline Trend over time, $\mathrm{Chi}^{2}$; p-value & $19.33(2) ; \mathrm{p}<.001$ & $1.26(2) ; p>.1$ \\
\hline Do the trends differ significantly? $\mathrm{Chi}^{2}(d f)$; $\mathrm{p}$-value & $14.20(2) ; \mathrm{p}<.001$ & \\
\hline \multicolumn{3}{|l|}{ Being hampered in social activities } \\
\hline $\mathrm{T} 0$, mean $(95 \% \mathrm{CI})^{\mathrm{a}}$ & $2.29(2.05-2.54)$ & $2.27(2.04-2.49)$ \\
\hline $\mathrm{T} 1$, mean $(95 \% \mathrm{Cl})^{\mathrm{a}}$ & $2.34(2.09-2.60)$ & $2.31(2.11-2.51)$ \\
\hline $\mathrm{T} 2$, mean $(95 \% \mathrm{CI})^{\mathrm{a}}$ & $2.50(2.25-2.75)$ & $2.43(2.24-2.62)$ \\
\hline Does $\mathrm{T} 1$ differ significantly from $\mathrm{T} 0$ ? $\mathrm{Chi}^{2}(d f) ; \mathrm{p}$-value & $0.20(1) ; p>.1$ & $0.20(1) ; p>.1$ \\
\hline Does T2 differ significantly from $\mathrm{T} 0$ ? $\mathrm{Ch}^{2}(d f)$; $\mathrm{p}$-value & $2.87(1) ; p>.05$ & $2.22(1) ; p>.1$ \\
\hline Trend over time, $\mathrm{Chi}^{2}(d f)$; $\mathrm{p}$-value & $2.90(2) ; p>.1$ & $2.54(2) ; p>.1$ \\
\hline Do the trends differ significantly? $\mathrm{Chi}^{2}(d f)$; $\mathrm{p}$-value & $0.09(2) ; \mathrm{p}>.1$ & \\
\hline \multicolumn{3}{|l|}{ Perceived general health status } \\
\hline T0, mean $(95 \% \mathrm{CI})^{\mathrm{a}}$ & $3.45(3.26-3.64)$ & $3.17(3.00-3.34)$ \\
\hline $\mathrm{T} 1$, mean $(95 \% \mathrm{Cl})^{\mathrm{a}}$ & $3.33(3.13-3.53)$ & $3.12(2.95-3.28)$ \\
\hline $\mathrm{T} 2$, mean $(95 \% \mathrm{CI})^{\mathrm{a}}$ & $3.22(3.04-3.41)$ & $3.28(3.12-3.44)$ \\
\hline Does $\mathrm{T} 1$ differ significantly from $\mathrm{T} 0 ? \mathrm{Chi}^{2}(d f) ; \mathrm{p}$-value & $1.59(1) ; p>.1$ & $0.35(1) ; p>.1$ \\
\hline Does T2 differ significantly from $\mathrm{T} 0$ ? $\mathrm{Ch}^{2}(d f)$; $\mathrm{p}$-value & $6.15(1) ; p<.05$ & $1.41(1) ; \mathrm{p}>.1$ \\
\hline Trend over time, $\mathrm{Chi}^{2}(d f)$; p-value & $6.15(2) ; p<.05$ & $3.11(2) ; p>.1$ \\
\hline Do the trends differ significantly? $\mathrm{Chi}^{2}(d f)$; $\mathrm{p}$-value & $7.56(2) ; p<.05$ & \\
\hline
\end{tabular}

${ }^{a}$ Corrected for region, sex, age, level of education, country of birth, migrant background, frequency of caregiving and self-perceived pressure from informal care. 